\title{
4
}

\section{Is Low Baroreflex Sensitivity only a Consequence of Essential Hypertension or also a Factor Conditioning Its Development?}

\author{
Natasa Honzikova and Eva Zavodna \\ Masaryk University, Faculty of Medicine, Department of Physiology \\ Czech Republic
}

\section{Introduction}

Baroreflex is the most important nervous regulatory mechanism of blood pressure homeostasis. Its role in a short-time regulation of blood pressure is very well documented. On the other hand, the answer to the question whether primary low baroreflex sensitivity could also be the cause of the development of hypertension remains unresolved. This question is now topical.

Baroreflex has several branches: reflex control of the peripheral resistance, of the tone of capacitance vessels, of the heart rate and contractility. Heart rate response to blood pressure variations is studied most intensively. Heart rate changes caused by stimulation of baroreceptors are usually quantified as the index of baroreflex sensitivity (BRS), which corresponds to a prolongation of the cardiac interval due to the increase of blood pressure in $\mathrm{ms} / \mathrm{mmHg}$. This mechanism operates beat-by-beat and is evaluated from recordings of blood pressure and inter-beat intervals (IBI) lasting for several minutes or several seconds respectively, depending on the method used. Despite the fact that BRS fluctuates in healthy subjects at rest, it represents a characteristic individual feature. Baroreflex sensitivity decreases with age and in different pathological states. This is of major clinical relevance as a risk factor of sudden cardiac death in patients after myocardial infarction, which is included among complications of hypertension. Therefore, many studies have paid attention to this problem providing evidence that metabolic and sympathetic/parasympathetic changes, especially during obesity, activate mechanisms (for instance thickening of the carotid wall) causing suppression of BRS. On the other hand, some healthy children and adolescents have as low BRS as elderly patients with hypertension. Some genetic studies provided evidence for an inborn disposition to low BRS. This opened the question whether an inborn low BRS could represent an additive factor disposing to blood pressure elevation. This is important with respect to epidemic obesity and to an increased prevalence of hypertension among young people.

We have proved by our own method of a summed-weighted-fuzzified index that low BRS is an index partially independent of obesity, which is linked with blood pressure elevation in young population (Krontoradova et al., 2008). 
In the methodological part of this Chapter, we describe a cross-spectral method of baroreflex sensitivity determination and the difference in the signification of this index determined in $\mathrm{ms} / \mathrm{mmHg}$ (BRS) as usual, or in $\mathrm{mHz} / \mathrm{mmHg}$ (BRSf). BRS is inter-beat interval-dependent and reflects best the total parasympathetic/sympathetic control of the heart rhythm. BRSf is inter-beat interval-independent and reflects preferably sensitivity of the baroreceptors. This fact is important when comparing groups of subjects with different mean inter-beat intervals, for instance, during childhood and adolescence.

\section{Baroreflex in short-term and long-term homeostasis of blood pressure}

The scientists proceeded from the observation that baroreceptors adapt to an increased blood pressure and are set to a higher level of blood pressure - the so-called resetting (Lohmeier et al., 2005). After baroreceptor denervation in experimental animals, blood pressure is increased by more than $50 \mathrm{mmHg}$, but during several days it resumes the original level due to the loss of blood volume by an increased urinary output. The result is an increase in blood pressure variability with the mean value of blood pressure corresponding to the value before the denervation. Based on the interpretation of these experiments it was concluded that the main function of baroreflex is the short-time regulation of blood pressure (Cowley et al., 1973). Only the recent experiments with chronic electrical stimulation of the carotid baroreceptor afferent nerve fibres and chronic recording of the renal sympathetic activity as well as some other experiments demonstrated the role of baroreceptors in the long-term control of blood pressure (Brooks \& Sved, 2005; Cowley et al., 1992; Thrasher, 2005). The therapy of chronic hypertension resistant to antihypertensive drugs by stimulation of carotid nerves confirmed that baroreflex is likewise effective in long-term blood pressure regulation (Filippone \& Bisognano, 2007).

\subsection{Measurement of heart rate baroreflex sensitivity}

The methods used to stimulate baroreceptors include administration of vasoconstrictive or vasodilative substances. The other possibility of stimulating baroreceptors is the so-called "neck suction". Another group of methods applies different mathematical procedures to the evaluation of recordings of blood pressure and inter-beat fluctuations which last several minutes. Baroreflex sensitivity calculated by different methods slightly differs (Laude et al., 2004; Persson et al., 2001).

In our laboratory, we published the first spectral analysis of blood pressure resting fluctuations in humans (Penaz et al., 1978). We have been using spectral analysis for baroreflex sensitivity determination since 1992 (Honzikova et al., 1992). Since then, we have obtained ample methodological experience and we would like to point out some of it.

\subsubsection{Cross-spectral method of baroreflex sensitivity determination}

At first, we can shortly describe our approach to the determination of baroreflex sensitivity using one of the options, the cross-spectral method.

The recordings of continuous blood pressure and of inter-beat interval duration (IBI) are quasi-periodical. Therefore a pre-processing is essential. The recording of blood pressure is digitized (for instance by a $250 \mathrm{~Hz}$ sampling rate and 12-bit resolution), and then stored. 
From the stored signal, the sequences of IBI, systolic blood pressure values (SBP), and diastolic blood pressure (DBP) are determined. The data acquired represent irregularly sampled values (concomitantly with variations of IBI) of a continuous time system. They are interpolated and equidistantly re-sampled.

The next step is a spectral analysis of these pre-processed data. There are two possibilities of evaluating the spectra: discrete Fourier transformation (DFT) applied directly on the signals and DFT applied to the autocorrelation function or the cross-correlation function of the signals. The latter method allows proving the legitimacy of the results by coherence. Therefore, we use this second method: the autocorrelation functions of IBI, SBP, DBP, and the cross-correlation function of IBI and SBP are calculated, and then, in the second step, the power spectra of the autocorrelation functions IBI, SBP and DBP, and the cross-spectrum of the cross-correlation function of IBI and SBP are calculated by fast Fourier transformation.

The gain factor between variations in systolic blood pressure and inter-beat intervals calculated at a frequency of $0.1 \mathrm{~Hz}$ is taken as a measure of baroreflex sensitivity (BRS) in ms/mmHg (Honzikova et al., 1992, 2003; Persson et al., 2001; Zavodna et al., 2006).

The frequency ranges between 0.07 and 0.012 , or between 0.05 and $0.15 \mathrm{~Hz}$, respectively, are used for the determination of BRS. The values of BRS are taken into account only if the coherence is higher than 0.5 (Fig. 1).

We calculate not only the BRS index in $\mathrm{ms} / \mathrm{mmHg}$, but also the BRSf index in $\mathrm{mHz} / \mathrm{mmHg}$. The reason for such approach is explained in detail in part 2.1.2 of this Chapter.

Continuous blood-pressure recordings are taken under different conditions. We use recordings at rest, in sitting position, during metronome-controlled breathing at a frequency of $0.33 \mathrm{~Hz}$ for about 5 minutes for the determination of the resting value of baroreflex sensitivity, or recordings at spontaneous breathing during a dynamic test, for instance workload, when controlled breathing is impossible.

During the testing of long duration, a time-frequency map of the spectra is computed. An example is given in Fig. 1, representing an experiment lasting 18 minutes: 3 minutes at rest (controlled breathing $0.33 \mathrm{~Hz}), 9$ minutes of bicycling $(0.5 \mathrm{~W} / \mathrm{kg}$ of body weight, spontaneous breathing), and $6 \mathrm{~min}$ at rest after exercise (Honzikova et al., 2003).

To get such a time course of the system properties the whole signal is processed in segments step by step from the beginning to the end.

The results of the time-frequency map of spectral analysis presented in Fig. 1 revealed two characteristic features. First, all calculated parameters - the frequency at which BRS was determined (f), the maximal power of the product of IBI and SBP spectral component (P), the selected maximal spectral components in a frequency range between 0.05 and $0.15 \mathrm{~Hz}$ of IBI and SBP (vIBI and vSBP), the time-shift between vIBI and vSBP spectral components in a frequency range between 0.05 and $0.15 \mathrm{~Hz}$, and baroreflex sensitivity fluctuate in time course. Second, for some short time intervals, coherence between variability of the signals is insignificant and so some data are omitted. Therefore, in principle, we never get identical values of these parameters during repeated measurements. Nevertheless, it was shown in several studies that there is a significantly lower intra-individual than inter-individual variability of BRS, SBP or IBI (Dietrich et al., 2010; Honzikova et al., 1990; Jira et al., 2006, 2010a; Penaz et al., 1978). 

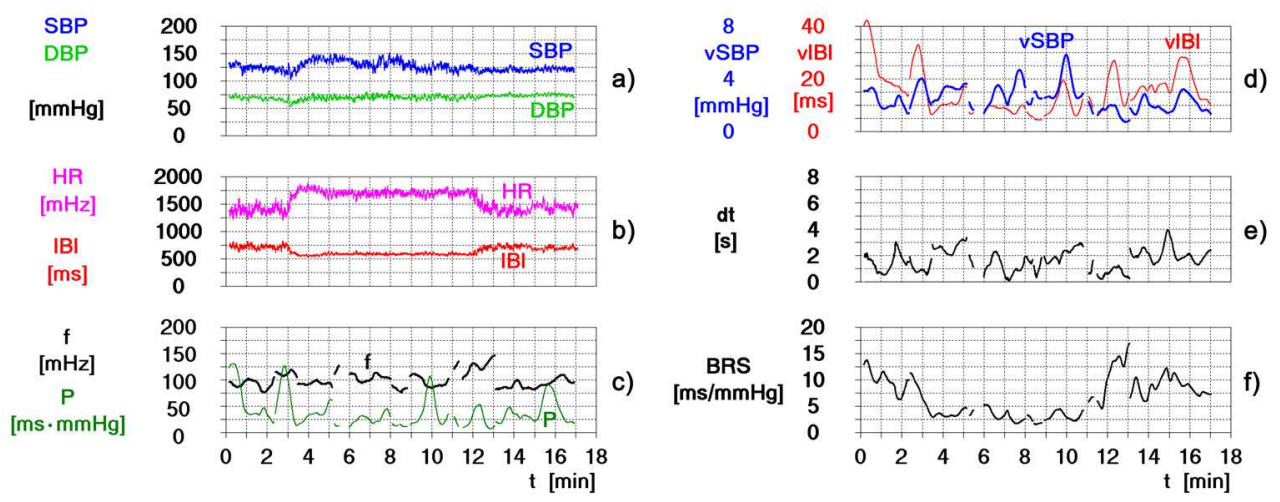

Fig. 1. An example of the time course of circulatory variables at rest $(3 \mathrm{~min}$, controlled breathing), during exercise ( $9 \mathrm{~min}$, spontaneous breathing), and during recovery ( $6 \mathrm{~min}$, controlled breathing). The individual graphs represent: a) the time course of the following parameters: systolic and diastolic blood pressure (SBP and DBP); b) inter-beat intervals and their inverse, heart rate values (IBI and HR); c) fluctuation of the frequency at which BRS was determined (f) with respect to the maximal power, i.e. the product of IBI and SBP spectral component amplitudes $(\mathrm{P}) ; \mathrm{d})$ the selected spectral components in the frequency range between 0.05 and $0.15 \mathrm{~Hz}$ of IBI and SBP (vIBI and vSBP); e) the time-shift between vIBI and vSBP spectral components in the frequency range between 0.05 and $0.15 \mathrm{~Hz}$; ) baroreflex sensitivity (BRS).

\subsubsection{Indices of baroreflex sensitivity calculated in $\mathrm{ms} / \mathrm{mmHg}$ and $\mathrm{mHz} / \mathrm{mmHg}$}

Baroreflex sensitivity can be expressed as the change of IBI due to a change of systolic blood pressure in $\mathrm{ms} / \mathrm{mmHg}$ (BRS index) or as the change of heart rate (HR) due to a change of systolic blood pressure in bpm/mmHg (Ackermann et al., 1989) or in $\mathrm{mHz} / \mathrm{mmHg}$ (Al Kubati et al., 1997). The BRS index is used in most studies, the second method is not used frequently, and there is no standard abbreviation for the indication that heart rate was used for the assessment of baroreflex sensitivity. In our laboratory, we apply calculation of baroreflex sensitivity in both units, in $\mathrm{ms} / \mathrm{mmHg}$ and in $\mathrm{mHz} / \mathrm{mmHg}$, and we use the abbreviations BRS and BRSf ( $\mathrm{f}$ in this abbreviation expresses that we use beat-to-beat values of heart rate for the calculation). To get the BRSf index $(\mathrm{mHz} / \mathrm{mm} \mathrm{Hg})$, it is necessary to calculate the value of a modulus at a frequency of $0.1 \mathrm{~Hz}$ in a similar way as in case of the BRS index using spectral analysis of instantaneous values of the heart rate measured beatby-beat and the corresponding systolic blood pressure values.

Even though in many dynamic tests or examinations of patients with severely suppressed baroreflex sensitivity the interpretation of the results is independent of the procedure (units) used, it is not so in all conditions. For example, examination of BRS and BRSf in 139 patients 7-14 days after the first signs of myocardial infarction had a similar discriminating significance between patients at risk and not at risk. Both indices were significantly decreased in patients who died within one year after examination in comparison with the survivors (Semrad et al., 1998). On the other hand, there is a difference in the age-related values of BRS and BRSf (Zavodna et al., 2006). 
It seems to be useful to explain our approach. The theoretical background is in a non-linear relationship between IBI and HR (in the scheme below there are big differences in mean IBI for a better demonstration of the effect discussed). The difference in the values of BRS and BRSf calculated at a different mean value of IBI is schematically presented in Fig. 2 (left).
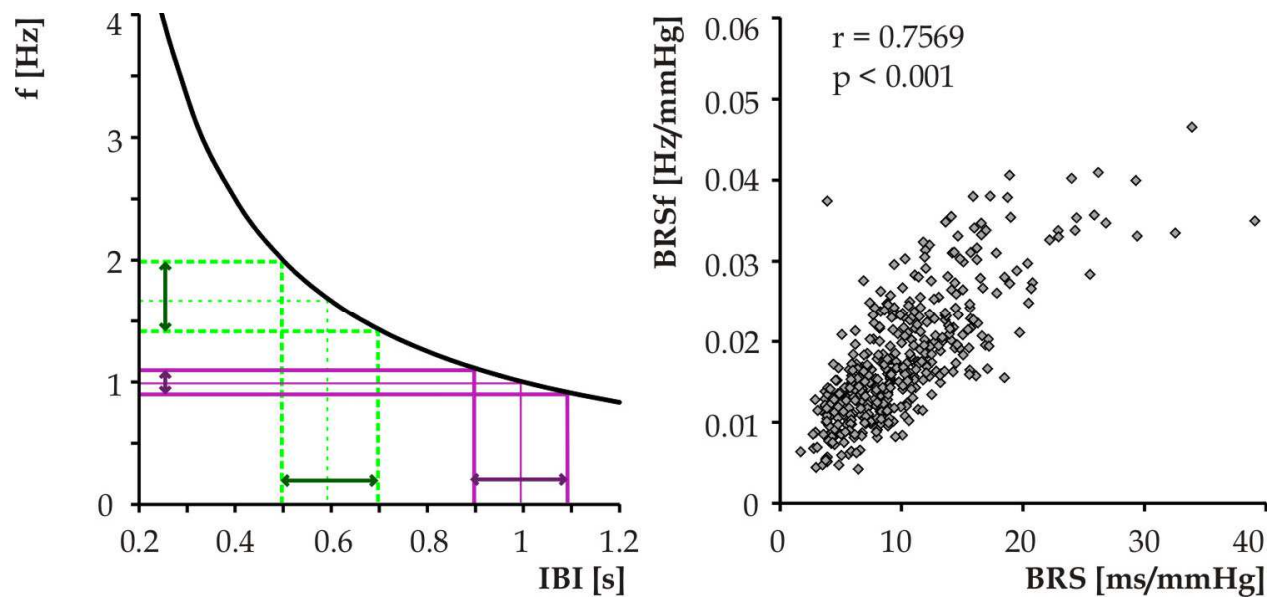

Fig. 2. Left: The non-linear relationship between IBI and HR influences BRS and BRSf indices presented by arrows. Right: The relationship between BRS and BRSf determined in 415 subjects (aged 11-20 years). The correlation coefficient calculated after normalization by a cube root.

Thus, with the same mean IBI in the two groups tested, the BRS index corresponds to the baroreflex responsiveness of the heart to blood pressure changes. Such a situation is very frequent, though mean IBI differs in individuals of such groups.

On the other hand, in a tested group with different mean IBI, the BRSf index should be preferred. For example, the effect of the development of parasympathetic control of the heart rate in childhood is manifested by prolongation of the mean IBI (Fig. 2 right). In the study of Zavodna et al. (2006), 415 healthy subjects at the age of 11-20 years were examined (under resting conditions, sitting, controlled breathing $0.33 \mathrm{~Hz}$ ). The BRS and BRSf indices were determined by the cross-spectral method at a frequency of $0.1 \mathrm{~Hz}$. BRS did not correlate with age, but BRSf significantly decreased with age. The baroreflex sensitivity determined as BRS in $\mathrm{ms} / \mathrm{mmHg}$ was significantly positively dependent on the mean IBI. This relationship was found not only in the whole group of subjects, but also in the respective age subgroups. A different situation was encountered in the relationship between baroreflex sensitivity expressed in $\mathrm{mHz} / \mathrm{mmHg}$ as BRSf and the mean IBI. BRSf correlated negatively with IBI in the age range between 11 to 20 years, but in the individual age subgroups the BRSf index was IBI independent. The greatest impact of IBI on baroreflex sensitivity was recorded in children aged 11-15 years in whom the mean IBI was prolonged with age. This means that the BRS index was influenced by the prolongation of mean IBI reflecting an age-dependent increased tonic vagal nerve activity. On the other hand, it could be hypothesized that BRSf better expressed the baroreceptor sensitivity. 
Some other studies also examined the problem of the relationship between the heart rate and BRS in children (Allen et al., 2000). It was proposed to standardize the patients' BRS to a fixed heart rate of 60 b.p.m. by regression (Abrahamsson et al., 2003). This approach has some limitation, because the linearity between log-BRS and heart rate is guaranteed only between the heart rates of 80 and 120 b.p.m. (Wesseling, 2003).

We decided to evaluate a suppression of systolic blood pressure variability by a baroreflex regulation of the heart rhythm at a frequency of $0.1 \mathrm{~Hz}$ using the BRS and BRSf indices (Honzikova et al., 2007). This study was performed in 58 subjects (20-22 years of age). SBP variability (SBPv) at $0.1 \mathrm{~Hz}$ (LF range) was used for statistical evaluation.

To enable a comparison of the quantitative effects of BRS and BRSf on SBPv, both variables were expressed as multiples of standard deviations. A negative correlation was found between SBPv and BRSsd and between SBPv and BRSfsd.

The multiple regression equation

$$
\mathrm{SBPv}=9.43-0.0052 * \mathrm{IBI} / \mathrm{ms}+0.15^{*} \mathrm{BRSsd}-1.85^{*} \mathrm{BRSfsd} ; \quad \mathrm{F}=2.92, \mathrm{p}<0.05
$$

revealed a higher regression coefficient of BRSfsd than the regression coefficient of BRSsd.

In conclusion, this analysis revealed that the inter-beat interval-independent index BRSf $(\mathrm{mHz} / \mathrm{mmHg})$ is a better indicator for evaluation of the efficacy of baroreflex sensitivity to suppress the SBP variability than the inter-beat interval-dependent index BRS (ms/mmHg).

\section{Physiology of baroreflex sensitivity}

\subsection{Resting heart rate baroreflex sensitivity as an individual characteristic feature and the influence of respiration}

Baroreflex sensitivity, heart rate, and blood pressure variability are closely interrelated. This is especially so in the case that all the three variables are determined at a frequency of 0.1 $\mathrm{Hz}$. This is the frequency range of a dominant role of baroreflex suppression of variations in blood pressure by heart rate changes. If the frequency range of respiration is included in a measurement or calculation, non-baroreflex factors are involved in respiratory sinus arrhythmia, such as a central component (Eckberg, 2003; Gilad et al., 2005; Eckberg \& Karemaker, 2009; Tzeng et al., 2009), afferent stimuli from stretch receptors in the lungs and thoracic wall (Taha et al., 1995), and resonance (van de Vooren et al., 2007). Thus, there is a difference between BRS values determined at a respiratory frequency and a frequency of 0.1 $\mathrm{Hz}$ (Bothova et al., 2010; Fredericks et al., 2000). Bothova et al. (2010) have shown that on average the determination of BRS by the spectral method at the breathing frequency overestimates the real BRS. This phenomenon was present only statistically and an opposite relationship can occur in some subjects. From the point of view of clinicians it is important that this effect is also present at low BRS values. Therefore, for diagnostic purposes we recommend the evaluation of BRS at a frequency of $0.1 \mathrm{~Hz}$ using metronome-controlled breathing at a frequency that is substantially higher than $0.1 \mathrm{~Hz}$ and is not a multiple of 0.1 $\mathrm{Hz}$ to eliminate the respiratory baroreflex-non-related influence and a resonance effect on heart rate fluctuations. 


\subsection{Physiology of baroreflex sensitivity in children and adolescents}

Relatively few studies of physiological BRS values in children and adolescents have been published. These studies indicate that BRS values are similar to those of young healthy adults and that inter-individual differences are also considerable. Quite different values of BRS were reported in 1868 children (10-13 years old) by Dietrich et al. (2006) - between 2.3 and $73 \mathrm{~ms} / \mathrm{mmHg}$. We found smaller differences in a group of 415 subjects 11-20 years old (Zavodna et al., 2006), ranging between $3.9 \mathrm{~ms} / \mathrm{mmHg}$ for the 5 th percentile and 18.7 $\mathrm{ms} / \mathrm{mmHg}$ for the 95 th percentile.

These results are surprising and change the view on the role of low BRS as a potentially primary factor involved in the early elevation of blood pressure. Low values of BRS in some children (Zavodna et al., 2006; Dietrich et al., 2006) approach the critical value for the risk of sudden cardiac death in patients after myocardial infarction and correspond to values present in hypertensive patients. BRS is usually less than $5 \mathrm{~ms} / \mathrm{mmHg}$ in hypertensive patients (Labrova et al., 2005) and BRS lower than $3 \mathrm{~ms} / \mathrm{mmHg}$ is a marker of an increased risk of sudden cardiac death in patients after myocardial infarction (La Rovere et al., 1998; Honzikova et al., 2000).

Concerning the age-dependent BRS, a decrease was repeatedly described in adults by many authors (Gribbin et al., 1971; Kardos et al., 2001). Fewer studies on BRS in children were published (Allen et al., 2000; Lenard et al., 2004; Rudiger et al., 2001). No significant agedependent baroreflex-sensitivity decrease was found in 400 subjects aged 10 to 19 years, as long as baroreflex sensitivity was expressed by the BRSf index in $\mathrm{mHz} / \mathrm{mmHg}$ or after normalization of BRS on the cardiac interval by multiple regression analysis (Zavodna et al., 2006). This can be explained by an increase in the parasympathetic tone and a prolongation of IBI, and this special approach was explained in part 2.1.2 of this Chapter.

\subsection{Genetics of BRS}

The genetic contribution to a BRS value could involve different components of the baroreceptor reflex arc, including baroreceptors, central neuronal transmission, reflex afferent and efferent pathways. In all of these there act numerous ligands, receptors, channels, etc. A serious understanding of genetically conditioned BRS will be very complicated because of multiple interactions of these factors.

Baroreceptors are mechanosensory nerve endings that innervate the adventitia of large arteries - the carotid and aortic sinus. An explanation of the conversion of mechanical energy into the action potential is still an open question. In the last two decades, a member of the degenerin family with mechanosensitive properties was detected in baroreceptor terminals: amiloride-sensitive epithelial Na channels (ENaC) (Drummond et al., 1998). The $\mathrm{ENaC}$ channels are usually under the aldosterone control. We might presume that aldosterone would increase $\mathrm{Na}+$ current in baroreceptor terminals and improve baroreceptor sensation of blood pressure rise. In the promotor region of the gene for enzyme 11/18-beta-hydroxylase (CYP11B2) in position -344 it is possible to find the C/T substitution which may influence the binding of regulatory factors (Lim et al., 2002). The T allele has been associated with increased plasma and urinary levels of aldosterone (Paillard et al., 1999; Davies et al., 1999), corresponding to the results of Ylitalo et al. (2000). They found, in a group of premenopausal women (41-46 years) who were TT homozygotes, increased mean 
and inter-individual variability of baroreflex sensitivity. The data are close to our unpublished data; however, we observed them in a group of young men (20-24 years) but not in women.

Gollasch et al. (2002) tested several mutations of the potassium large conductance calciumactivated channel (KCNMB1) and showed that individuals having SNP AA in exon $4 \mathrm{~b}$ had greater baroreflex slopes in the high-frequency range than had CA or CC subjects. Their findings suggest that potassium channel heterogeneity could mainly influence the rapid baroreflex-mediated adjustment of heart rate by the parasympathetic nervous system. This idea is also supported by Pedarzani et al. (2000), who documented the presence of very high levels of $\alpha$-subunit potassium channel mRNA in rat dorsal vagal neurons.

The processing of the baroreceptor input is mediated in the CNS by several neurotransmitters, especially by angiotensin II. Generally, angiotensin II has a sympathoexcitatory effect. It was shown that long-term intracerebroventricular infusion of angiotensin II decreased BRS in rabbits, but therapy with the angiotensin blocker losartan resulted in BRS increase (Gaudet et al., 2000). We have found in our group of healthy young subjects (20-24 years) an association between the less frequent homozygotes CC and decreased baroreflex sensitivity (Jira et al., 2010b).

There are also other studies that were more or less successful in the association of the mutation in genes with blood pressure variability and its buffering via the baroreflex pathway, e.g. endothelin (Ormezzano et al., 2005), acid sensing ion channel (Lu et al., 2009), neuropeptide Y1 receptor (Wang et al., 2009), eNOS (Jira et al., 2011), etc.

\section{Low baroreflex sensitivity as a risk factor}

\subsection{Significance of low baroreflex sensitivity as a risk factor}

The significance of a short-time blood pressure regulation by high BRS as a protection of an ischemic myocardium from the risk of sudden cardiac death was shown about 15 years ago and BRS lower than $3 \mathrm{~ms} / \mathrm{mmHg}$ was determined as the critical value of BRS (Honzikova et al., 2000; La Rovere et al., 1998). At high BRS, a quick prolongation of IBI following a sudden blood pressure elevation decreases cardiac workload. This is important in an ischemic myocardium, especially after myocardial infarction, and therefore high BRS prevents sudden cardiac death.

Myocardial infarction is a frequent complication of essential hypertension. Studies of BRS in hypertensive patients are important with respect to the potential risk of hypertensive patients in a possible situation of a later myocardial infarction. BRS is usually lower than 5 $\mathrm{ms} / \mathrm{mmHg}$ in hypertensive patients (Cowley, 1992; Labrova et al., 2005; Thrasher et al., 2005). Different comorbidities (diabetes mellitus or heart failure) have an additive effect either by decreasing BRS, or increasing the risk of myocardial infarction (Mortara et al., 1997).

Patients at risk of sudden cardiac death profit from implantation of an implantable cardioverter-defibrillator (ICD). Indication for ICD implantation is done invasively. It would be desirable to develop a non-invasive approach to risk stratification of patients. Many trials were carried out to find a combination of non-invasive risk-stratification techniques for identifying the patients at risk. Although the low left ventricular ejection fraction has been 
used effectively to select high-risk patients for the application of therapy to prevent sudden cardiac death, it has a limited sensitivity. Reviews of nearly 15 non-invasive markers of high-risk patients also include BRS (Bailey et al., 2007; Goldberger et al., 2008).

\subsection{Logit and fuzzy models in risk-data analysis}

Multiregression analysis is used for evaluation of the influence of different factors on some functional states, as well as the logistic regression analysis and calculation of the odds ratio for a group of risk factors. Such approach provides the basic information, for instance for the understanding of the pathogenesis of any process. Medical practice very often needs not only identification of risk predictors, but also determination of their critical values, sensitivity, specificity, and a positive predictive value in the diagnostics or a therapeutic decision in patients. Calculation of the receiver operating curve (ROC) is used for this purpose. The improvement of the predictive power of a group of risk factors needs to take the following physiological assumptions into account. First, the edge between a risky and a non-risky value of each predictor is not an exact value; secondly, different risk predictors have different weight.

We have developed fuzzified and weighted models for a sum of risk predictors (Honzik et al., 2003, 2010). First, ROC and the area under ROC were determined for each single predictor. The measure of the increasing risk of each single predictor was determined with one fuzzy set of data with an output range from 0 to 1 . The fuzzy weighted method multiplied each individual risk of each predictor with the predictor's area under ROC. The final measure of the risk of each patient was determined as the sum of partial fuzzified weighted risks of individual predictors. These new individual predictors were also evaluated by ROC and the area under ROC. For each predictor (measured predictors and a new fuzzified-weighted-summed predictor) critical values, sensitivity, specificity, and positive predictive values were calculated. Our new fuzzified-weighted-summed predictor favourably affected the predictive power of non-invasive risk predictors in individuals. This approach can be applied in similar decision processes (Krontoradova et al., 2008).

\section{Low baroreflex sensitivity due to factors associated with hypertension}

\subsection{Low BRS and the increased stiffness of the carotid wall}

The association between BRS and intima-media thickness (IMT) in the carotid bulb, a region with high baroreceptor density, was shown as a marker of subclinical atherosclerosis and essential hypertension (Gianaros et al., 2002; Honzikova et al., 2006a; Labrova et al., 2005; Zanchetti et al. 1998). Carotid IMT also correlated with age in people who were not hypertensives (Labrova et al., 2005). Besides intimal thickening due to the atherosclerotic process, smooth muscle hypertrophy and/or hyperplasia may develop due to a pressure overload in hypertensive patients. Thus, remodelling of the carotid wall linked to high blood pressure and an increased stiffness of the carotid sinus leads to lower distensibility of the baroreceptor carotid region during blood pressure increase. BRS is also inversely associated with the relative wall thickness and the left ventricular mass index, and is significantly impaired in hypertensive patients with concentric left ventricular remodelling (Milan et al., 2007). All these findings suggest that BRS is a target in arterial hypertension. 
As mentioned above, we determined baroreflex sensitivity in hypertensive patients not only by the BRS index, but also using the BRSf index. Hypertensive patients had thicker IMT and lower both indices of baroreflex sensitivity, BRS and BRSf, than healthy controls (Labrova et al., 2005). The positive correlation between age and IMT, the negative correlation between age and BRS and BRSf, and the positive correlation between IMT and BMI in healthy subjects were in agreement with the hypothesis that the age-dependent decrease of baroreflex sensitivity corresponded to the age-related structural changes of the carotid wall. A different situation appeared in hypertensive patients. We did not see any additive thickening of their IMT or any decrease of BRS with age, but BRSf decreased significantly with age. IMT in hypertensive patients was not additively influenced by age or BMI. This means that the additive influence of age on baroreflex sensitivity in hypertensive patients could be detected by the BRSf index only. Using two indices of baroreflex sensitivity, BRS and BRSf, we were able to show that baroreflex sensitivity in hypertensives is lower not only due to thickening of the carotid wall, but also due to ageing (Labrova et al., 2005; Honzikova et al., 2006).

The examination of the BRSf index implies the question whether low BRS in hypertensive patients is only a secondary effect of the mechanisms described above or whether an individually inborn low BRS could participate in the development of hypertension.

\subsection{Obesity, sympathetic activation and hypertension}

The relationship between obesity and a higher risk of high blood pressure was established for both adults and children in dozens of studies, (e.g. Krontoradova et al., 2008; Lurbe et al., 1998; Rahmouni et al., 2005). The Framingham study brought evidence of the prevalence of hypertension in obese individuals, which was twice that of individuals of normal weight, across all ages in men and women (Hubert et al., 1983). It was also reported in several studies that weight loss in hypertensive subjects lowered blood pressure (Gordon et al., 1997; Kriketos et al., 2001; Neter et al., 2003), though the results of some studies showed that blood pressure decrease related to weight loss could be only transient (Laaksonen et al., 2003). Also, white coat hypertension is more frequent in individuals with overweight (Helvaci et al., 2007; Honzikova et al., 2006).

Nowadays, the prevalence of obesity increases not only in adults, but also in adolescents. It is hypothesized that it could be linked with increased prevalence of hypertension in adolescents and young adults. The data on the epidemics of obesity are alarming. Data from 45 pairs of surveys from 11 countries were analysed in studies by Lobstein \& Jackson-Leach (2006). Annual increases in the prevalence of overweight (including obesity) rose from typically below 0.5 percentage points in the 1980 s to over 1.0 percentage points in the late 1990s. The variations across countries may relate to changes and differences in the key environmental factors (Wang et al., 2002).

More mechanisms leading to blood pressure increase in obese subjects have been described. Many studies have documented that sympathetic activation takes part in linking obesity to hypertension. Particularly, intra-abdominal obesity is a major risk factor for cardiovascular morbidity and mortality. It seems that leptin plays a key role. Leptin is a hormone secreted by adipocytes and its blood concentration is proportional to the fat mass content. It acts in the hypothalamus and, besides controlling the body weight by a suppression of food intake 
and stimulating the metabolic rate, it also increases sympathetic nervous activity. Hypertension in obesity is explained by a selective leptin resistance to the appetite reducing activity, but by preservation of the sympathetic activation and the sympathetic action on the kidney. Thus, chronic hyperleptinemia in obesity produces hypertension. Sympathetic activation is linked with an activation of the renin-angiotensin system (RAS) in obesity. Adipocyte-derived angiotensinogen can act locally to effect adipocyte growth and differentiation, and thus it can partially attribute to the increased fat mass (Rahmouni et al., 2005). It can be also secreted into the blood stream (Rahmouni et al., 2005). Rahmouni et al. (2004) found in mice with obesity induced by high-fat diet greater angiotensinogen gene expression in the intra-abdominal fat but not in other fat depots or non-adipose tissue. As regards visceral obesity and hypertension, high circulating levels of free fatty acids in obese subjects are involved in sympathetic activation. They are released into the portal vein from lipolysis in visceral fat depots, and this could explain the association between visceral obesity and sympathetic activation (Rahmouni et al., 2005).

The elevated circulating leptin is associated with impaired baroreflex function. BRS is reduced in obese children (Lazarova et al., 2009). Leptin receptors are present on vagal afferent fibres and neurons within the solitary tract nucleus, providing an anatomic distribution consistent with baroreflex modulation. It was shown in experiments in rats that leptin microinjection at sites within the solitary tract nucleus impairs the baroreflex sensitivity for bradycardia induced by increases in arterial pressure (Arnold et al., 2009).

In addition to the effects on homeostasis of body weight and sympathetic activity, leptin has a broad range of effects in different tissues. The effect on glucose homeostasis supports the development of type II diabetes mellitus, and this is an additive mechanism related to blood pressure elevation and BRS decrease.

Endothelial dysfunction such as decreased nitric oxide (NO) responsiveness is also a common abnormality in obesity. Damage to the endothelium leads to structural changes of the vessel wall such as thickening of the intima-media of the vessel wall (Rahmouni et al., 2005). Usually, this mechanism is accepted as a principal one in a decreased BRS because of a low compliance of the arterial wall where baroreceptors are present. However, it is necessary to take into account the effect of $\mathrm{NO}$ activity involved in low frequency variability in circulation.

There are data showing that NO is involved in the control of blood pressure variability (BPV) via release of NO by endothelial cells (Just et al., 1994; Nafz et al., 1997). The greatest difference in BPV was reported in a frequency range of 0.1 to $0.5 \mathrm{~Hz}$ in dogs and 0.2 to 0.6 in rats, i.e. a frequency range in which the sympathetic nervous system is most effective. NO buffers blood pressure fluctuations by opposing the sympathetic nervous activity (Stauss et al., 2000). Moreover, Hogan et al. (1999) demonstrated nitric oxide as a possible factor which causes a significant reduction in the diastolic and systolic blood pressure low-frequency power by infusion of the NO donor sodium nitroprusside in humans. In this experiment, the hypotensive action of sodium nitroprusside was prevented by phenylephrine, but a reduction in the BP low-frequency power persisted. This corresponds to the fact that in carriers of less frequent alleles enhanced BPV was observed at a frequency of $0.1 \mathrm{~Hz}$, which is the frequency of sympathetic activity in humans (Jira et al., 2011).

Many genetically hypothetic mechanisms could be involved in the pathophysiology of the individual disposition for an increase of blood pressure in dependence on obesity. However, 
they seldom show a linkage between obesity and variability in circulation in a frequency range of $0.1 \mathrm{~Hz}$ or baroreflex sensitivity.

Fatso/fat mass and obesity associated gene (FTO gene) was established as contributing to obesity. It is expressed in the hypothalamus and influences energy metabolism. Since hypothalamus is also involved in blood pressure regulation, the relationship of polymorphism of the FTO gene to blood pressure control was studied (Pausova et al., 2009). It was found in this study, carried out nearly in 500 adolescents, that individuals with the FTO-risk genotype, compared with those who lacked it, demonstrated greater adiposity, including the amount of intra-abdominal fat, higher systolic blood pressure, and a higher sympathetic modulation of the vasomotor tone evaluated as a variability of diastolic blood pressure in a frequency range of $0.1 \mathrm{~Hz}$ by spectral analysis. It was hypothesized that sex differences and inter-individual differences in linking intra-abdominal obesity to hypertension could be explained by mechanisms of action of androgens. Voluminous intraabdominal fat, higher blood pressure, and a prominent sympathetic modulation of the vasomotor tone (evaluated as a variability of diastolic blood pressure in a frequency range of $0.1 \mathrm{~Hz}$ by spectral analysis) were found in boys aged 12 to 18 years, who had a low CAGrepeat number in the androgen-receptor gene in comparison with those with a high CAGrepeat number. No such differences were seen among girls. This study documented not only that this gene represents a genetic risk factor for linkage between intra-abdominal obesity and hypertension, but also that sympathoactivation may be an underlying link between these states (Pausova et al., 2010).

\section{Low BRS as a factor causing blood pressure elevation in adolescents}

\subsection{Prevalence of hypertension and white coat hypertension in children and adolescents}

The concept of white coat hypertension is used in situations when blood pressure measured at a causal office examination is elevated, but is within the physiological range during its repeated measurement or a 24-hour blood-pressure measurement. Some authors believe that white coat hypertension does not require pharmacological therapy (Cavallini et al., 1995), but an increased risk of cardiovascular diseases was reported in other studies (Gustavsen et al., 2003; Lande et al., 2008).

Prevalence of white coat hypertension is relatively high in different countries in both adults and children. Prevalence of white coat hypertension was higher in obese children, but differences as to age or sex were insignificant (Stabouli et al., 2005). Dozens of studies have brought similar results. Elevation of blood pressure mainly concerns its systolic value. The difference measured in diastolic blood pressure could be conditioned by the technical difficulty of its measurement, especially in small children (Hornsby et al., 1991). Nowadays, ambulatory blood pressure measurement is a standard for the diagnostics of white coat hypertension.

\subsection{Primary low baroreflex sensitivity as an additive factor of blood pressure elevation in children and adolescents}

Recently, several studies have shown that an increase in the body mass index (BMI) correlates significantly with the elevation of blood pressure and a decrease of BRS. 
Differences in the BMI, BRS/BRSf indices, mean IBI, and systolic blood pressure variability were compared in healthy controls, adolescents with white coat hypertension, and hypertensive adolescents (Honzikova et al., 2006b). The stepwise blood pressure elevation in these groups was associated with a stepwise increase of BMI and a stepwise decrease of both indices of baroreflex sensitivity, BRS and BRSf; the mean IBI was unchanged. Systolic blood pressure variability was increased in hypertonic adolescents only.

Such a finding may correspond with the idea that subclinical atherosclerosis and a remodelling of the vascular wall may develop very early, though the finding of a similarly lower BRS in children, adolescents and young adults with white coat hypertension suggests a contradicting interpretation. This group of young subjects with white coat hypertension has a physiological blood pressure over 24 hours and there is no reason for remodelling the vascular wall. Nevertheless, they have lower BRS than healthy controls and BRSf as well. These results suggest the only interpretation, namely that low BRS precedes blood pressure elevation (Honzikova et al., 2009).

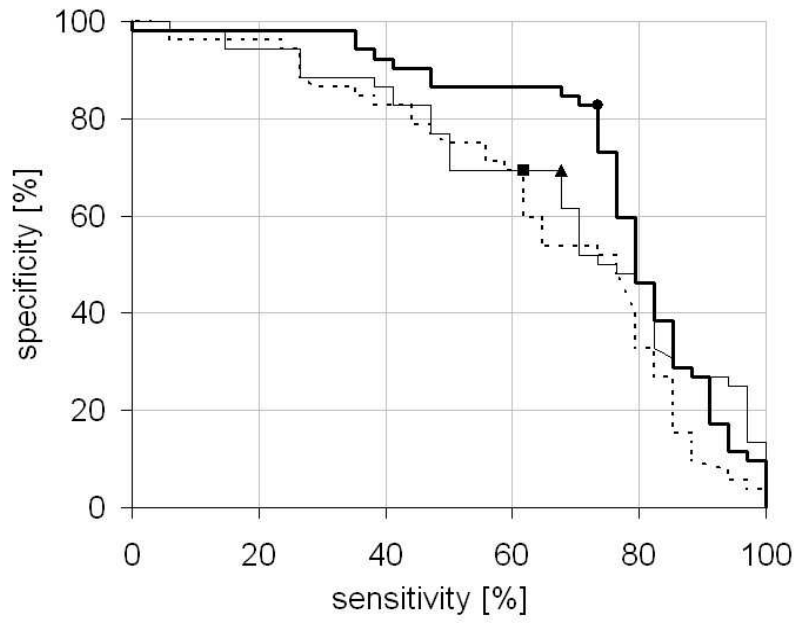

Fig. 3. Receiver operating curves of baroreflex sensitivity (BRS, thin line), body mass index (BMI, dashed line), and a combination of both factors (full line). Optimal critical values determined as values at which the maximum achievable combination of sensitivity and specificity was reached: $7.08 \mathrm{~ms} / \mathrm{mmHg}$ for BRS (triangle), $22.20 \mathrm{~kg} / \mathrm{m}^{2}$ for BMI (square), and 0.439 normalized units for a combination of BMI and BRS (point). Reproduced with permission of Physiological Research.

Direct evidence that low baroreflex sensitivity is a partially independent risk factor for the development of essential hypertension was provided by Krontoradova et al. (2008). In this study hypertonic subjects had a significantly lower BRS and a significantly higher BMI (the BRSf index was not evaluated with respect to the same mean IBI in controls and hypertonics). On the other hand, no correlation was found between BMI and BRS either in the group of hypertonics or in controls. The predicting power of BMI, BRS, and a combination of both factors determined by logistic regression analysis for hypertension was evaluated by sensitivity and specificity. The optimal critical values were determined by the 
receiver operating curves (ROC), i.e. a plot of sensitivity versus specificity for moving critical values in steps. Also, the area under the ROC curve was calculated. The approach described in part 4.2 of this Chapter was applied for the evaluation of association of decreased BRS and increased BMI with a risk of hypertension. The sensitivity, specificity and area under ROC were increased for a combination of both factors, BRS and BMI, in predicting hypertension (see Fig. 3).

This means that low BRS may serve as an independent risk factor for the development of essential hypertension. What mechanism of blood pressure elevation due to individually low BRS could be taken into consideration? Stressing situations increase the sympathetic nervous activity as well as blood pressure. Blood pressure elevation is partially blunted by the heart rate baroreflex response. This suppression of blood pressure increase is insufficient in children with low BRS; therefore, white coat hypertension occurs and frequent vasoconstrictive reactions could lead to the development of essential hypertension after a longer time.

\section{Conclusion}

Baroreflex sensitivity is, to a certain extent, an individually characteristic index. It fluctuates spontaneously even at rest and therefore, regardless of how it is further processed mathematically, a particular value measured represents an approximate estimate of its size. On the other hand, low values of baroreflex sensitivity are highly repeatable in some individuals, and it is just the low BRS values that pose a risk for the development of hypertension and its complications. Bearing in mind the fact that essential hypertension is a disease of higher age, the majority of studies done in previous years were naturally focused on baroreflex sensitivity in older population. The increased arterial stiffness, increased IMT, and sympathetic activation in obesity represent indubitable factors which lead to hypertension and, consequently, result in a decrease of BRS. The hypothesis ensuing from these studies, which states that the drop in baroreflex sensitivity accompanies the development of hypertension as a secondary manifestation of the disease, is proved by these studies. Low baroreflex sensitivity is then a risk factor in further complications of the disease, particularly after myocardial infarction. Also, the pathophysiological mechanism of protection of the myocardium from ischemia through high baroreflex sensitivity is obvious. Quick prolongation of IBI following a sudden blood pressure elevation decreases cardiac workload.

On the other hand, measurements of BRS in children and adolescents and the first genetic studies on the inborn conditionality of BRS have provided enough evidence that some individuals possess congenitally low baroreflex sensitivity. This condition does not mean any risk for a healthy organism. Without a targeted study, we cannot even speculate on how this assumption will manifest itself in advanced age in terms of increased risk of sudden cardiac death, since in the meantime the long-term pathological influence of other mechanisms lowering baroreflex sensitivity will have presented itself in the other risky patients.

However, low baroreflex sensitivity apparently represents a risk. It is probably a further factor which disposes an individual towards blood pressure elevation. Low baroreflex sensitivity will manifest itself as blood pressure hyperreactivity. It may lead to white coat 
hypertension in adolescents as a step in the development of essential hypertension. Therefore, congenitally low baroreflex sensitivity may be considered as another risk factor for the development of essential hypertension. This is the reason why in the young population, including children and adolescents with low baroreflex sensitivity, increased emphasis should be put on the prevention of obesity and sufficient physical activity as on easily influenceable stimuli which additively increase blood pressure.

Measuring baroreflex sensitivity is a simple, in no way stressful, non-invasive method. It requires just a couple of minutes taking non-invasive record of blood pressure by means of a pressure cuff applied on a finger and subsequent mathematical processing. However, if a BRS determination is to provide the presumed relevant clinical information, it is not that easy. BRS evaluation in the young may only be carried out on the basis of repeated measurements. In child age and adolescence, it is appropriate to take into account the average heart rate when quantifying BRS. One of the possibilities is the BRSf index or some other adequate method. This area of research is therefore substantial from the point of view of the study of baroreflex sensitivity, prevention of hypertension and its severe complications, and may be of significance for preventative medicine.

\section{Acknowledgement}

This study was supported by grant MSM 0021622402 from the Ministry of Education, Youth and Sports of the Czech Republic. We gratefully acknowledge A. Krticka for help with the methodology part.

\section{References}

Abrahamsson, C., Ahlund, C., Nordlander, M. \& Lind, L. (2003). A method for heart ratecorrected estimation of baroreflex sensitivity. Journal of Hypertension, Vol. 21, No. 11, (November 2003), pp. 2133-2140, ISSN 02636352

Ackermann, U., Irizawa, T.G. \& Barber. B. (1989). Angiotensin restores atrial natriuretic factor-induced decrease of baroreceptor sensitivity in normotensive rats, but not in spontaneously hypertensive rats. Canadian Journal of Physiology and Pharmacology, Vol. 67, No. 6, (June 1989), pp. 675-81, ISSN 00084212

Al-Kubati, M.A.A., Fiser, B. \& Siegelova, J. (1997). Baroreflex sensitivity during psychological stress. Physiological Research, Vol. 46, No. 1, (February 1997), pp. 2733, ISSN 08628408

Allen, M.T., Matthews, K.A. \& Kenyon, K.L. (2000). The relationships of resting baroreflex sensitivity, heart rate variability and measures of impulse control in children and adolescents. International Journal of Psychophysiology, Vol. 37, No. 2, (August 2000), pp. 185-194, ISSN 01678760

Arnold, A.C., Shaltout, H.A., Gallagher, P.E. \& Diz, D.I. (2009). Leptin impairs cardiovagal baroreflex function at the level of the solitary tract nucleus. Hypertension, Vol. 54, No. 5, (November 2009), pp. 1001-1008, ISSN 0194911X

Bailey, J.J., Hodges, M. \& Church, T.R. (2007). Decision to implant a cardioverter defibrillator after myocardial infarction: The role of ejection fraction v. other risk factor markers. Medical Decision Making, Vol. 27, No. 2, (March 2007), pp. 151-160, ISSN 0272989X 
Bothova, P., Honzikova, N., Fiser, B., Zavodna, E., Novakova, Z., Kalina, D., Honzikova, K. \& Labrova, R. (2010). Comparison of baroreflex sensitivity determined by crossspectral analysis at respiratory and $0.1 \mathrm{~Hz}$ frequencies in man. Physiological Research, Vol. 59, Suppl. 1, (May 2010), pp. S103-111, ISSN 08628408

Brooks, V.L. \& Sved, A.F. (2005). Pressure to change? Re-evaluating the role of baroreceptors in the long-term control of arterial pressure. American Journal of Physiology Regulatory Integrative and Comparative Physiology, Vol. 288, No. 4 57-4, (April 2005), pp. R815-R818, ISSN 03636119

Cavallini, M.C., Roman, M.J., Pickering, T.G., Schwartz, J.E., Pini, R. \& Devereux, R.B. (1995). Is white coat hypertension associated with arterial disease or left ventricular hypertrophy? Hypertension, Vol. 26, No. 3, (September 1995), pp. 413-419, ISSN 0194911X

Cowley Jr., A.W. (1992). Long-term control of arterial blood pressure. Physiological Reviews, Vol. 72, No. 1, (January 1992), pp. 231-280, ISSN 00319333

Cowley Jr., A.W., Liard, J.F. \& Guyton, A.C. (1973). Role of baroreceptor reflex in daily control of arterial blood pressure and other variables in dogs. Circulation Research, Vol. 32, No. 5, (May 1973), pp. 564-576, ISSN 00097330

Davies, E., Holloway, C.D., Ingram, M.C., Inglis, G.C., Friel, E.C., Morrison, C., Anderson, N.H., Fraser, R. \& Connell, J.M.C. (1999). Aldosterone excretion rate and blood pressure in essential hypertension are related to polymorphic differences in the aldosterone synthase gene CYP11B2. Hypertension, Vol. 33, No. 2, (February 1999), pp. 703-707, ISSN 0194911X

Dietrich, A., Riese, H., Van Roon, A.M., Van Engelen, K., Ormel, J., Neeleman, J. \& Rosmalen, J.G.M. (2006). Spontaneous baroreflex sensitivity in (pre)adolescents. Journal of Hypertension, Vol. 24, No. 2, (February 2006), pp. 345-352, ISSN 02636352

Dietrich, A., Rosmalen, J.G.M., Althaus, M., van Roon, A.M., Mulder, L.J.M., Minderaa, R.B., Oldehinkel, A.J. \& Riese, H. (2010). Reproducibility of heart rate variability and baroreflex sensitivity measurements in children. Biological Psychology, Vol. 85, No. 1, (September 2010), pp. 71-78, ISSN 03010511

Drummond, H.A., Price, M.P., Welsh, M.J. \& Abboud, F.M. (1998). A molecular component of the arterial baroreceptor mechanotransducer. Neuron, Vol. 21, No. 6, (December 1998), pp. 1435-1441, ISSN 08966273

Eckberg, D.L. (2003). The human respiratory gate. Journal of Physiology, Vol. 548, No. 2, (April 2003), pp. 339-352, ISSN 00223751

Eckberg, D.L. \& Karemaker, J.M. (2009). Point:Counterpoint: Respiratory sinus arrhythmia is due to a central mechanism vs. respiratory sinus arrhythmia is due to the baroreflex mechanism. Journal of Applied Physiology, Vol. 106, No. 5, (May 2009), pp. 1740-1744, ISSN 87507587

Filippone, J.D. \& Bisognano, J.D. (2007). Baroreflex stimulation in the treatment of hypertension. Current Opinion in Nephrology and Hypertension, Vol. 16, No. 5, (September 2007), pp. 403-408, ISSN 10624821

Frederiks, J., Swenne, C.A., TenVoorde, B.J., Honzikova, N., Levert, J.V., Maan, A.C., Schalij, M.J. \& Bruschke, A.V.G. (2000). The importance of high-frequency paced breathing in spectral baroreflex sensitivity assessment. Journal of Hypertension, Vol. 18, No. 11, (November 2000), pp. 1635-1644, ISSN 02636352

Gaudet, E., Godwin, S.J. \& Head, G.A. (2000). Effects of central infusion of ANG II and losartan on the cardiac baroreflex in rabbits. American Journal of Physiology - Heart 
and Circulatory Physiology, Vol. 278, No. 2 47-2, (February 2000), pp. H558-H566, ISSN 03636135

Gianaros, P.J., Jennings, J.R., Olafsson, G.B., Steptoe, A., Sutton-Tyrrell, K., Muldoon, M.F. \& Manuck, S.B. (2002). Greater intima-media thickness in the carotid bulb is associated with reduced baroreflex sensitivity. American Journal of Hypertension, Vol. 15, No. 6, (June 2002), pp. 486-491, ISSN 08957061

Gilad, O., Swenne, C.A., Davrath, L.R. \& Akselrod, S. (2005). Phase-averaged characterization of respiratory sinus arrhythmia pattern. American Journal of Physiology - Heart and Circulatory Physiology, Vol. 288, No. 2 57-2, (February 2005), pp. H504-H510, ISSN 03636135

Goldberger, J.J., Cain, M.E., Hohnloser, S.H., Kadish, A.H., Knight, B.P., Lauer, M.S., Maron, B.J., Page, R.L., Passman, R.S., Siscovick, D., Stevenson, W.G. \& Zipes, D.P. (2008). American Heart Association/American College of Cardiology Foundation/Heart rhythm society scientific statement on noninvasive risk stratification techniques for identifying patients at risk for sudden cardiac death: A scientific statement from the American heart association council on clinical cardiology committee on electrocardiography and arrhythmias and council on epidemiology and prevention. Circulation, Vol. 118, No. 14, (September 2008), pp. 1497-1518, ISSN 00097322

Gollasch, M., Tank, J., Luft, F.C., Jordan, J., Maass, P., Krasko, C., Sharma, A.M., Busjahn, A. \& Bahring, S. (2002). The BK channel $\beta 1$ subunit gene is associated with human baroreflex and blood pressure regulation. Journal of Hypertension, Vol. 20, No. 5, (May 2002), pp. 927-933, ISSN 02636352

Gordon, N.F., Scott, C.B. \& Levine, B.D. (1997). Comparison of single versus multiple lifestyle interventions: Are the antihypertensive effects of exercise training and diet-induced weight loss additive? American Journal of Cardiology, Vol. 79, No. 6, (March 1997), pp. 763-767, ISSN 00029149

Gribbin, B., Pickering, T.G., Sleight, P. \& Peto, R. (1971). Effect of age and high blood pressure on baroreflex sensitivity in man. Circulation Research, Vol. 29, No. 4, (October 1971), pp. 424-431, ISSN 00097330

Gustavsen, P.H., Hoegholm, A., Bang, L.E. \& Kristensen, K.S. (2003). White coat hypertension is a cardiovascular risk factor: A 10-year follow-up study. Journal of Human Hypertension, Vol. 17, No. 12, (December 2003), pp. 811-817, ISSN 09509240

Helvaci, M.R., Kaya, H., Yalcin, A. \& Kuvandik, G. (2007). Prevalence of white coat hypertension in underweight and overweight subjects. International Heart Journal, Vol. 48, No. 5, (November 2007), pp. 605-613, ISSN 13492365

Hogan, N., Kardos, A., Paterson, D.J. \& Casadei, B. (1999). Effect of exogenous nitric oxide on baroreflex function in humans. American Journal of Physiology - Heart and Circulatory Physiology, Vol. 277, No. 1 46-1, (July 1999), pp. H221-H227, ISSN 03636135

Honzik, P., Hrabec, J., Labrova, R., Semrad, B. \& Honzikova, N. (2003). Fuzzification, weight and summation of risk factors in a patient improve the prediction of risk for cardiac death. Scripta Medica, Vol. 76, No. 3, (June 2003), pp. 141-148, ISSN 12113395

Honzik, P., Krivan, L., Lokaj, P., Labrova, R., Novakova, Z., Fiser, B. \& Honzikova, N. (2010). Logit and fuzzy models in data analysis: Estimation of risk in cardiac patients. Physiological Research, Vol. 59, Suppl. 1, (May 2010), pp. S89-96, ISSN 08628408 
Honzikova, N., Penaz, J. \& Fiser, B. (1990). Individual features of circulatory power spectra in man. European Journal of Applied Physiology, Vol. 59, No. 6, pp. 430-434, ISSN 03015548

Honzikova, N., Fiser, B. \& Honzik, J. (1992). Noninvasive determination of baroreflex sensitivity in man by means of spectral analysis. Physiological Research, Vol. 41, No. 1, (February 1992), pp. 31-37, ISSN 08628408

Honzikova, N., Rybkova, I. \& Honzik, J. (1996). Baroreflex sensitivity, heart rate and blood pressure during mental load and emotional activation. Homeostasis in Health and Disease, Vol. 37, No. 1-2, (April 1996), pp. 72-76, ISSN 09607560

Honzikova, N., Semrad, B., Fiser, B. \& Labrova, R. (2000). Baroreflex sensitivity determined by spectral method and heart rate variability, and two-years mortality in patients after myocardial infarction. Physiological Research, Vol. 49, No. 6, (November 2000), pp. 643-650, ISSN 08628408

Honzikova, N., Krticka, A., Novakova, Z. \& Zavodna, E. (2003). A dampening effect of pulse interval variability on blood pressure variations with respect to primary variability in blood pressure during exercise. Physiological Research, Vol. 52, No. 3, (June 2003), pp. 299-309, ISSN 08628408

Honzikova, N., Labrova, R., Fiser, B., Maderova, E., Novakova, Z., Zavodna, E. \& Semrad, B. (2006a). Influence of age, body mass index, and blood pressure on the carotid intima-media thickness in normotensive and hypertensive patients. Biomedizinische Technik, Vol. 51, No. 4, (October 2006), pp. 159-162, ISSN 00135585

Honzikova, N., Novakova, Z., Zavodna, E., Paderova, J., Lokaj, P., Fiser, B., Balcarkova, P. \& Hrstkova, H. (2006b). Baroreflex sensitivity in children, adolescents, and young adults with essential and white-coat hypertension. Klinische Padiatrie, Vol. 218, No. 4, (July-August 2006), pp. 237-242, ISSN 03008630

Honzikova, N., Fiser, B., Zavodna, E., Novakova, Z. \& Krticka, A. (2007). Effectiveness of suppression of systolic blood pressure variability by baroreflex. Clinical Autonomic Research, Vol. 17, No. 5, (October 2007), pp. 281, ISSN 0959-9851

Honzikova, N. \& Fiser, B. (2009). Baroreflex sensitivity and essential hypertension in adolescents. Physiological Research, Vol. 58, No. 5, (October 2009), pp. 605-612, ISSN 08628408

Hornsby, J.L., Mongan, P.F., Taylor, A.T. \& Treiber, F.A. (1991). 'White coat' hypertension in children. Journal of Family Practice, Vol. 33, No. 6, (June 1991), pp. 617-623, ISSN 00943509

Hubert, H.B., Feinleib, M., McNamara, P.M. \& Castelli, W.P. (1983). Obesity as an independent risk factor for cardiovascular disease: A 26-year follow-up of participants in the Framingham heart study. Circulation, Vol. 67, No. 5, (May 1983), pp. 968-977, ISSN 00097322

Jackson-Leach, R. \& Lobstein, T. (2006). Estimated burden of paediatric obesity and comorbidities in Europe. Part 1. The increase in the prevalence of child obesity in Europe is itself increasing. International Journal of Pediatric Obesity, Vol. 1, No. 1, (January 2006), pp. 26-32, ISSN 17477166

Jira, M., Zavodna, E., Honzikova, N., Novakova, Z. \& Fiser, B. (2006). Baroreflex sensitivity as an individual characteristic feature. Physiological Research, Vol. 55, No. 3, (June 2006), pp. 349-351, ISSN 08628408 
Jira, M., Zavodna, E., Novakova, Z., Fiser, B. \& Honzikova, N. (2010a). Reproducibility of blood pressure and inter-beat interval variability in man. Physiological Research, Vol. 59, Suppl. 1, (May 2010), pp. S113-121, ISSN 08628408

Jira, M., Zavodna, E., Honzikova, N., Novakova, Z., Vasku, A., Izakovicova Holla, L. \& Fiser, B. (2010b). Association of A1166C polymorphism in AT1 receptor gene with baroreflex sensitivity. Physiological Research, Vol. 59, No. 4, (August 2010), pp. 517528, ISSN 08628408

Jira, M., Zavodna, E., Honzikova, N., Novakova, Z., Vasku, A., Holla, L.I. \& Fiser, B. (2011). Association of eNOS gene polymorphisms T-786C and G894T with blood pressure variability in man. Physiological Research, Vol. 60, No. 1, (February 2011), pp. 193197, ISSN 08628408

Just, A., Wittmann, U., Nafz, B., Wagner, C.D., Ehmke, H., Kirchheim, H.R. \& Persson, P.B. (1994). The blood pressure buffering capacity of nitric oxide by comparison to the baroreceptor reflex. American Journal of Physiology - Heart and Circulatory Physiology, Vol. 267, No. 2 36-2, (August 1994), pp. H521-H527, ISSN 03636135

Kardos, A., Rudas, L., Gingl, Z., Szabados, S. \& Simon, J. (1995). The mechanism of blood pressure variability. Study in patients with fixed ventricular pacemaker rhythm. European Heart Journal, Vol. 16, No. 4, (April 1995), pp. 545-552, ISSN 0195668X

Kardos, A., Watterich, G., De Menezes, R., Csanady, M., Casadei, B. \& Rudas, L. (2001). Determinants of spontaneous baroreflex sensitivity in a healthy working population. Hypertension, Vol. 37, No. 3, (March 2001), pp. 911-916, ISSN 0194911X

Kriketos, A.D., Robertson, R.M., Sharp, T.A., Drougas, H., Reed, G.W., Storlien, L.H. \& Hill, J.O. (2001). Role of weight loss and polyunsaturated fatty acids in improving metabolic fitness in moderately obese, moderately hypertensive subjects. Journal of Hypertension, Vol. 19, No. 10, (October 2001), pp. 1745-1754, ISSN 02636352

Krontoradova, K., Honzikova, N., Fiser, B., Novakova, Z., Zavodna, E., Hrstkova, H. \& Honzik, P. (2008). Overweight and decreased baroreflex sensitivity as independent risk factors for hypertension in children, adolescents, and young adults. Physiological Research, Vol. 57, No. 3, (June 2008), pp. 385-391, ISSN 08628408

La Rovere, M.T., Bigger Jr., J.T., Marcus, F.I., Mortara, A. \& Schwartz, P.J. (1998). Baroreflex sensitivity and heart-rate variability in prediction of total cardiac mortality after myocardial infarction. Lancet, Vol. 351, No. 9101, (February 1998), pp. 478-484, ISSN 01406736

Laaksonen, D.E., Laitinen, T., Schönberg, J., Rissanen, A. \& Niskanen, L.K. (2003). Weight loss and weight maintenance, ambulatory blood pressure and cardiac autonomic tone in obese persons with the metabolic syndrome. Journal of Hypertension, Vol. 21, No. 2, (February 2003), pp. 371-378, ISSN 02636352

Labrova, R., Honzikova, N., Maderova, E., Vysocanova, P., Novakova, Z., Zavodna, E., Fiser, B. \& Semrad, B. (2005). Age-dependent relationship between the carotid intima-media thickness, baroreflex sensitivity, and the inter-beat interval in normotensive and hypertensive subjects. Physiological Research, Vol. 54, No. 6, (December 2005), pp. 593-600, ISSN 08628408

Lande, M.B., Meagher, C.C., Fisher, S.G., Belani, P., Wang, H. \& Rashid, M. (2008). Left ventricular mass index in children with white coat hypertension. Journal of Pediatrics, Vol. 153, No. 1, (July 2008), pp. 50-54, ISSN 00223476

Laude, D., Elghozi, J.-L., Girard,A., Bellard, E., Bouhaddi, M., Castiglioni, P., Cerutti, C., Cividjian, A., Di Rienzo, M., Fortrat, J.O., Janssen, B., Karemaker, J.M., Leftheriotis, 
G., Parati, G., Persson, P.B., Porta, A., Quintin, L., Regnard, J., Rudiger, H., Stauss, H.M. (2004). Comparison of various techniques used to estimate spontaneous baroreflex sensitivity (the EUROBAVAR study). American Journal of Physiology. Regulatory, Integrative and Comparative Physiology, Vol. 286, No. 1, (January 2004), pp. R226-R231, ISSN 0363-6119

Lazarova, Z., Tonhajzerova, I., Trunkvalterova, Z., Brozmanova, A., Honzikova, N., Javorka, K., Baumert, M. \& Javorka, M. (2009). Baroreflex sensitivity is reduced in obese normotensive children and adolescents. Canadian Journal of Physiology and Pharmacology, Vol. 87, No. 7, (July 2009), pp. 565-571, ISSN 00084212

Lenard, Z., Studinger, P., Mersich, B., Kocsis, L. \& Kollai, M. (2004). Maturation of cardiovagal autonomic function from childhood to young adult age. Circulation, Vol. 110, No. 16, (October 2004), pp. 2307-2312, ISSN 00097322

Lim, P.O., Macdonald, T.M., Holloway, C., Friel, E., Anderson, N.H., Dow, E., Jung, R.T., Davies, E., Fraser, R. \& Connell, J.M.C. (2002). Variation at the aldosterone synthase (CYP11B2) locus contributes to hypertension in subjects with a raised aldosteroneto-renin ratio. Journal of Clinical Endocrinology and Metabolism, Vol. 87, No. 9, (September 2002), pp. 4398-4402, ISSN 0021972X

Lobstein, T. \& Jackson-Leach, R. (2006). Estimated burden of paediatric obesity and comorbidities in Europe. Part 2. Numbers of children with indicators of obesityrelated disease. International Journal of Pediatric Obesity, Vol. 1, No. 1, (January 2006), pp. 33-41, ISSN 17477166

Lohmeier, T.E., Hildebrandt, D.A., Warren, S., May, P.J. \& Cunningham, J.T. (2005). Recent insights into the interactions between the baroreflex and the kidneys in hypertension. American Journal of Physiology - Regulatory Integrative and Comparative Physiology, Vol. 288, No. 4, (April 2005), pp. R828-R836, ISSN 03636119

Lu, Y., Ma, X., Sabharwal, R., Snitsarev, V., Morgan, D., Rahmouni, K., Drummond, H.A., Whiteis, C.A., Costa, V., Price, M., Benson, C., Welsh, M.J., Chapleau, M.W. \& Abboud, F.M. (2009). The ion channel ASIC2 is required for baroreceptor and autonomic control of the circulation. Neuron, Vol. 64, No. 6, (December 2009), pp. 885-897, ISSN 08966273

Lurbe, E., Alvarez, V., Liao, Y., Tacons, J., Cooper, R., Cremades, B., Torro, I. \& Redon, J. (1998). The impact of obesity and body fat distribution on ambulatory blood pressure in children and adolescents. American Journal of Hypertension, Vol. 11, No. 4 I, (April 1998), pp. 418-424, ISSN 08957061

Milan, A., Caserta, M.A., Del Colle, S., Dematteis, A., Morello, F., Rabbia, F., Mulatero, P., Pandian, N.G. \& Veglio, F. (2007). Baroreflex sensitivity correlates with left ventricular morphology and diastolic function in essential hypertension. Journal of Hypertension, Vol. 25, No. 8, (August 2007), pp. 1655-1664, ISSN 02636352

Mortara, A., La Rovere, M.T., Pinna, G.D., Prpa, A., Maestri, R., Febo, O., Pozzoli, M., Opasich, C. \& Tavazzi, L. (1997). Arterial baroreflex modulation of heart rate in chronic heart failure: clinical and hemodynamic correlates and prognostic implications. Circulation, Vol. 96, No. 10, (November 1997), pp. 3450-3458, ISSN 0009-7322

Nafz, B., Wagner, C.D. \& Persson, P.B. (1997). Endogenous nitric oxide buffers blood pressure variability between 0.2 and $0.6 \mathrm{hz}$ in the conscious rat. American Journal of Physiology - Heart and Circulatory Physiology, (February 1997), pp. H632-H637, ISSN 03636135 
Neter, J.E., Stam, B.E., Kok, F.J., Grobbee, D.E. \& Geleijnse, J.M. (2003). Influence of weight reduction on blood pressure: A meta-analysis of randomized controlled trials. Hypertension, Vol. 42, No. 5, (November 2003), pp. 878-884, ISSN 0194911X

Ormezzano, O., Poirier, O., Mallion, J., Nicaud, V., Amar, J., Chamontin, B., Mounier-Vehier, C., François, P., Cambien, F. \& Baguet, J.P. (2005). A polymorphism in the endothelin-A receptor gene is linked to baroreflex sensitivity. Journal of Hypertension, Vol. 23, No. 11, (November 2005), pp. 2019-2026, ISSN 02636352

Paillard, F., Chansel, D., Brand, E., Benetos, A., Thomas, F., Czekalski, S., Ardaillou, R. \& Soubrier, F. (1999). Genotype-phenotype relationships for the renin-angiotensinaldosterone system in a normal population. Hypertension, Vol. 34, No. 3, (September 1999), pp. 423-429, ISSN 0194911X

Pausova, Z., Syme, C., Abrahamowicz, M., Xiao, Y., Leonard, G.T., Perron, M., Richer, L., Veillette, S., Smith, G.D., Seda, O., Tremblay, J., Hamet, P., Gaudet, D. \& Paus, T. (2009). A common variant of the FTO gene is associated with not only increased adiposity but also elevated blood pressure in French Canadians. Circulation: Cardiovascular Genetics, Vol. 2, No. 3, (May 2009), pp. 260-269, ISSN 1942325X

Pausova, Z., Abrahamowicz, M., Mahboubi, A., Syme, C., Leonard, G.T., Perron, M., Richer, L., Veillette, S., Gaudet, D. \& Paus, T. (2010). Functional variation in the androgenreceptor gene is associated with visceral adiposity and blood pressure in male adolescents. Hypertension, Vol. 55, No. 3, (March 2010), pp. 706-714, ISSN 0194911X

Pedarzani, P., Kulik, A., Muller, M., Ballanyi, K. \& Stocker, M. (2000). Molecular determinants of $\mathrm{Ca} 2+$-dependent $\mathrm{K}+$ channel function in rat dorsal vagal neurones. Journal of Physiology, Vol. 527, No. 2, (September 2000), pp. 283-290, ISSN 00223751

Penaz, J., Honzikova, N. \& Fiser, B. (1978). Spectral analysis of resting variability of some circulatory parameters in man. Physiologia Bohemoslovaca, Vol. 27, No. 4, (August 1978), pp. 349-357, ISSN 03699463

Persson, P.B., DiRienzo, M., Castiglioni, P., Cerutti, C., Pagani, M., Honzikova, N., Akselrod, S. \& Parati, G. (2001). Time versus frequency domain techniques for assessing baroreflex sensitivity. Journal of Hypertension, Vol. 19, No. 10, (October 2001), pp. 1699-1705, ISSN 02636352

Rahmouni, K., Correia, M.L.G., Haynes, W.G. \& Mark, A.L. (2005). Obesity-associated hypertension: New insights into mechanisms. Hypertension, Vol. 45, No. 1, (January 2005), pp. 9-14, ISSN 0194911X

Rahmouni, K., Mark, A.L., Haynes, W.G. \& Sigmund, C.D. (2004). Adipose depot-specific modulation of angiotensinogen gene expression in diet-induced obesity. American Journal of Physiology - Endocrinology and Metabolism, Vol. 286, No. 6 49-6, (June 2004), pp. E891-E895, ISSN 01931849

Rudiger, H. \& Bald, M. (2001). Spontaneous baroreflex sensitivity in children and young adults calculated in the time and frequency domain. Autonomic Neuroscience: Basic and Clinical, Vol. 93, No. 1-2, (October 2001), pp. 71-78, ISSN 15660702

Semrad, B., Fiser, B. \& Honzikova, N. (1998). Aging and cardiac autonomic status, In: Clinical guide to cardiac autonomic tests, Malik, M., (Ed.), pp. (285-300), Kluwer Academic Publishers, ISBN 0-7923-5178-9, The Netherlands.

Stabouli, S., Kotsis, V., Toumanidis, S., Papamichael, C., Constantopoulos, A. \& Zakopoulos, N. (2005). White-coat and masked hypertension in children: Association with 
target-organ damage. Pediatric Nephrology, Vol. 20, No. 8, (August 2005), pp. 11511155, ISSN 0931041X

Stauss, H.M. \& Persson, P.B. (2000). Role of nitric oxide in buffering short-term blood pressure fluctuations. News in Physiological Sciences, Vol. 15, No. 5, (October 2000), pp. 229-233, ISSN 08861714

Taha, B.H., Simon, P.M., Dempsey, J.A., Skatrud, J.B. \& Iber, C. (1995). Respiratory sinus arrhythmia in humans: An obligatory role for vagal feedback from the lungs. Journal of Applied Physiology, Vol. 78, No. 2, (February 1995), pp. 638-645, ISSN 87507587

Thrasher, T.N. (2005). Effects of chronic baroreceptor unloading on blood pressure in the dog. American Journal of Physiology - Regulatory Integrative and Comparative Physiology, Vol. 288, No. 4 57-4, (April 2005), pp. R863-R871, ISSN 03636119

Tzeng, Y.C., Sin, P.Y.W., Lucas, S.J.E. \& Ainslie, P.N. (2009). Respiratory modulation of cardiovagal baroreflex sensitivity. Journal of Applied Physiology, Vol. 107, No. 3, (September 2009), pp. 718-724, ISSN 87507587

Van De Vooren, H., Gademan, M.G.J., Swenne, C.A., TenVoorde, B.J., Schalij, M.J. \& Van der Wall, E.E. (2007). Baroreflex sensitivity, blood pressure buffering, and resonance: What are the links? Computer simulation of healthy subjects and heart failure patients. Journal of Applied Physiology, Vol. 102, No. 4, (April 2007), pp. 1348-1356, ISSN 87507587

Wang, L., Rao, F., Zhang, K., Mahata, M., Rodriguez-Flores, J.L., Fung, M.M., Waalen, J., Cockburn, M.G., Hamilton, B.A., Mahata, S.K. \& O'Connor, D.T. (2009). Neuropeptide Y1 receptor NPY1R discovery of naturally occurring human genetic variants governing gene expression in cells as well as pleiotropic effects on autonomic activity and blood pressure in vivo. Journal of the American College of Cardiology, Vol. 54, No. 10, (September 2009), pp. 944-954, ISSN 07351097

Wesseling, K.H. (2003). Should baroreflex sensitivity be corrected for heart rate? Journal of Hypertension, Vol. 21, No. 11, (November 2003), pp. 2015-2018, ISSN 02636352

Ylitalo, A., Juhani Airaksinen, K.E., Hautanen, A., Kupari, M., Carson, M., Virolainen, J., Savolainen, M., Kauma, H., Antero Kesaniemi, Y., White, P.C. \& Huikuri, H.V. (2000). Baroreflex sensitivity and variants of the renin angiotensin system genes. Journal of the American College of Cardiology, Vol. 35, No. 1, (January 2000), pp. 194200, ISSN 07351097

Zanchetti, A., Bond, M.G., Hennig, M., Neiss, A., Mancia, G., Dal Palu, C., Hansson, L., Magnani, B., Rahn, K., Reid, J., Rodicio, J., Safar, M., Eckes, L. \& Ravinetto, R. (1998). Risk factors associated with alterations in carotid intima-media thickness in hypertension: Baseline data from the European lacidipine study on atherosclerosis. Journal of Hypertension, Vol. 16, No. 7, (July 1998), pp. 949-961, ISSN 02636352

Zavodna, E., Honzikova, N., Hrstkova, H., Novakova, Z., Moudr, J., Jira, M. \& Fiser, B. (2006). Can we detect the development of baroreflex sensitivity in humans between 11 and 20 years of age? Canadian Journal of Physiology and Pharmacology, Vol. 84, No. 12, (December 2006), pp. 1275-1283, ISSN 00084212 


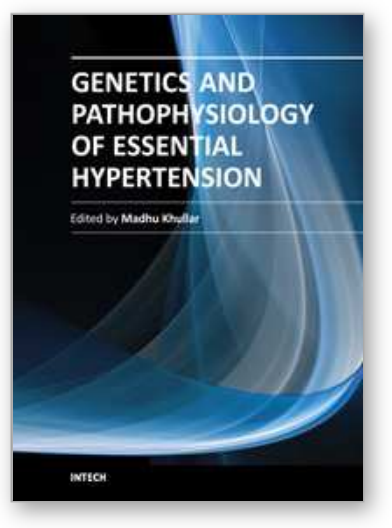

\author{
Genetics and Pathophysiology of Essential Hypertension \\ Edited by Prof. Madhu Khullar
}

ISBN 978-953-51-0282-3

Hard cover, 236 pages

Publisher InTech

Published online 09, March, 2012

Published in print edition March, 2012

This book, authored by renowned researchers in the field of Hypertension Research, details the state of the art knowledge in genetics, genomics and pathophysiology of Essential hypertension, specifically the genetic determinants of hypertension and role of gene variants in response to anti-hypertensive therapy. Two chapters describe mitochondrial mutations in Essential hypertension and in hypertension associated Left ventricular hypertrophy, one chapter reviews in detail the global gene expression in hypertension, and an up to date treatise on pathophysiology of resistant hypertension is detailed in another chapter. Other topics included in the book are end organ damage, baroreceptor sensitivity and role of music therapy in essential hypertension.

\title{
How to reference
}

In order to correctly reference this scholarly work, feel free to copy and paste the following:

Natasa Honzikova and Eva Zavodna (2012). Is Low Baroreflex Sensitivity only a Consequence of Essential Hypertension or also a Factor Conditioning Its Development?, Genetics and Pathophysiology of Essential Hypertension, Prof. Madhu Khullar (Ed.), ISBN: 978-953-51-0282-3, InTech, Available from:

http://www.intechopen.com/books/genetics-and-pathophysiology-of-essential-hypertension/is-low-baroreflexsensitivity-only-a-consequence-of-essential-hypertension-or-also-a-factor-conditio

\section{INTECH}

open science | open minds

\section{InTech Europe}

University Campus STeP Ri

Slavka Krautzeka 83/A

51000 Rijeka, Croatia

Phone: +385 (51) 770447

Fax: +385 (51) 686166

www.intechopen.com

\section{InTech China}

Unit 405, Office Block, Hotel Equatorial Shanghai

No.65, Yan An Road (West), Shanghai, 200040, China

中国上海市延安西路65号上海国际贵都大饭店办公楼 405 单元

Phone: +86-21-62489820

Fax: +86-21-62489821 
(C) 2012 The Author(s). Licensee IntechOpen. This is an open access article distributed under the terms of the Creative Commons Attribution 3.0 License, which permits unrestricted use, distribution, and reproduction in any medium, provided the original work is properly cited. 